\title{
Self-Estimated functional inability because of pain questionnaire for workers: a reliability and construct validity study
}

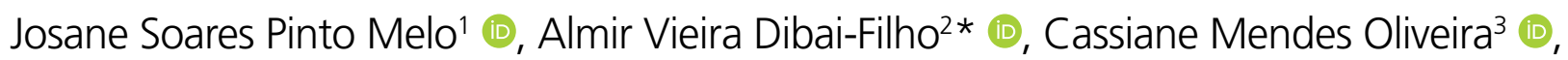 \\ Cezar Augusto Brito Pinheiro ${ }^{4}$ (), Daniel Santos Rocha ${ }^{3}$ (1) , Gabriela Nascimento de Santana ${ }^{5}$, \\ Cid André Fidelis de Paula Gomes ${ }^{5}$ (D), Daniela Bassi-Dibai ${ }^{1}$ (1)
}

\begin{abstract}
SUMMARY
OBJECTIVE: The objective of this study was to investigate the reliability and construct validity of the Self-Estimated Functional Inability because of Pain questionnaire for workers in a sample of Brazilian workers with musculoskeletal pain.

METHODS: This is a questionnaire validation study. Workers with musculoskeletal pain were included. Besides the Self-Estimated Functional Inability because of Pain questionnaire for workers, we used the following instruments to perform construct validity: the Work Ability Index and the Numerical Pain Rating Scale. A subsample answered the Self-Estimated Functional Inability because of Pain questionnaire for workers in two moments to calculate reliability by means of the intraclass correlation coefficient and internal consistency by means of the Cronbach's alpha.

RESULTS: A total of 190 Brazilian workers were included. Regarding the construct validity, we observed a correlation with magnitude above 0.50 between the Self-Estimated Functional Inability because of Pain questionnaire for workers and the Numerical Pain Rating Scale, given that these two instruments have similarity in the construct, and correlations above 0.30 between the Self-Estimated Functional Inability because of Pain questionnaire for workers and the domains 2, 3, and 4 of the Work Ability Index. Regarding reliability, we observed adequate reliability (intraclass correlation coefficient $=0.864$ ) and internal consistency (Cronbach's alpha=0.807).

CONCLUSION: The Self-Estimated Functional Inability because of Pain questionnaire for workers is a reliable and valid instrument to be used in Brazilian workers with musculoskeletal pain.

KEYWORDS: Pain. Surveys and questionnaires. Reproducibility of results.
\end{abstract}

\section{INTRODUCTION}

Self-report measures are important and routinely used by researchers and health professionals to analyze occupational dysfunctions and gestures ${ }^{1}$. Considering pain complaints and musculoskeletal disorders, the most commonly used instrument for these purposes in research and in the clinical and occupational environments is the Nordic Musculoskeletal Questionnaire (NMQ). This instrument organizes musculoskeletal pain complaints in a regionalized

\footnotetext{
'Universidade Ceuma, Postgraduate Program in Programs Management and Health Services - São Luís (MA), Brazil.

¿Universidade Federal do Maranhão, Postgraduate Program in Physical Education - São Luís (MA), Brazil.

${ }^{3}$ Universidade Ceuma, Department of Physical Therapy - São Luís (MA), Brazil.

${ }^{4}$ Universidade Federal do Maranhão, Department of Physical Education - São Luís (MA), Brazil.

${ }^{5}$ Universidade Nove de Julho, Postgraduate Program in Rehabilitation Sciences - São Paulo (SP), Brazil.

*Corresponding author: dibaifilho@gmail.com

Conflicts of interest: the authors declare there are no conflicts of interest. Funding: National Council for Scientific and Technological Development (PIBIC/CNPq), the Foundation for Research Support and Scientific and Technological Development of Maranhão (PIBIC/FAPEMA), and the Coordination for the Improvement of Higher Education Personnel (CAPES, finance code 001).

Received on July 16, 2021. Accepted on August 14, 2021.
} 
manner, considering body parts ${ }^{2}$. However, the limitation of the NMQ is that it does not present a numeric pain or disability score.

In this study, we analyzed a new instrument that was recently created with the aim of measuring musculoskeletal pain and disability in Brazilian workers: the Self-Estimated Functional Inability because of Pain (SEFIP-work) ${ }^{3}$. This questionnaire allows the regionalized analysis of pain and disability in the body, as well as the NBQ, however, with the positive aspect of generating interpretable numerical scores. The SEFIP was initially developed and validated to investigate the musculoskeletal injuries in dancers (SEFIP-dance) ${ }^{4,5}$. However, due to its broad structure, this questionnaire has been adapted for athletes (SEFIP-sport) ${ }^{5,6}$ and for workers (SEFIP-work) ${ }^{3}$.

Considering only the SEFIP-work, the pioneer study conducted by Pinheiro et al. ${ }^{3}$ evaluated only the content validity. However, other measurement properties need to be investigated to properly support the use of the SEFIP-work in the occupational context $^{7}$. Thus, the present study focuses on this gap in the literature, aiming to investigate the reliability and construct validity of the SEFIP-work in a sample of Brazilian workers. Our hypothesis is that this instrument presents acceptable measurement properties.

\section{METHODS}

\section{Ethical aspects and study design}

The research was conducted by means of an online platform (Google Forms, Mountain View, CA, USA) with Brazilian workers with musculoskeletal pain and was based at the Universidade Ceuma (São Luís, MA, Brazil). The study procedures were approved by the ethics committee in research of the institution (opinion number: 3.779.579).

This is a questionnaire validation study carried out in accordance with the recommendations of the Consensus-based Standards for the Selection of Health Measurement Instruments (COSMIN) ${ }^{7}$.

\section{Participants}

To calculate the sample size, the minimum recommendation of 100 participants were used ${ }^{8}$. The inclusion criteria were workers active for at least 6 months in the same job, aged 18 or above, able to read and write in Brazilian Portuguese, and with musculoskeletal pain. The participants excluded from the study were workers diagnosed with severe cognitive and/or psychiatric illnesses, and workers away from the work environment.

\section{Self-Estimated Functional Inability because of Pain questionnaire for workers-work}

The questionnaire consists of 14 items, each item related to a body part, and Likert score for each item (0-4). Thus, the total score varies between 0 and 56 points; the higher the score, the higher the disability. In addition to this total score, we calculated a separate score for each body region to produce a score from 0 (no disability) to 4 (maximum disability). The version of the SEFIP-work in Brazilian Portuguese and English are available in a previous study ${ }^{3}$.

\section{Others instruments}

The Work Ability Index (WAI) was used to measure the ability to work. This instrument was adapted to the Brazilian Portuguese? and consists of seven domains: domain 1 , ability to work at present and compared to the best in life ( $0-10$, score); domain 2 , ability to work in relation to the job requirements $(2-10$, score); domain 3 , current number of self-reported and physician-diagnosed illnesses (1-7, score); domain 4, estimated loss for work due to the illnesses (1-6, score); domain 5 , absence from work due to the illnesses (1-5, score); domain 6 , own prognosis about work ability (1-7, score); and domain 7 , mental resources (1-4, score).

The 11-point Numerical Pain Rating Scale (NPRS) was used to measure the highest pain intensity in the body, where 0 means "no pain" and 10 represents "the most excruciating pain." This instrument has been validated for Portuguese ${ }^{10}$.

\section{Statistical analysis}

Descriptive analysis was used to characterize the sample, with the presentation of quantitative data using mean and standard deviation and qualitative data using number and percentage.

The test-retest reliability was determined by means of the intraclass correlation coefficient (ICC), standard error of measurement (SEM), and minimum detectable change (MDC). The ICC value was considered adequate when greater than $0.75^{11}$. Value between 0.70 and 0.95 was considered adequate for Cronbach's alpha ${ }^{8}$.

To determine the validity of the construct, Spearman's correlation coefficient (rho) was used to determine the magnitude of the correlation between the SEFIP-work, WAI, and NPRS. Our hypothesis is that the SEFIP-work score presents a correlation magnitude greater than 0.50 with the NPRS (similar construct) and between 0.50 and 0.30 with the domains of the WAI (related but dissimilar constructs), as described by the COSMIN 7 .

Data processing was performed using SPSS, version 17.0 (Chicago, IL, USA). All analyses were performed considering a significance level of $5 \%$.

\section{RESULTS}

A total of 190 Brazilian workers were included in the study. The characterization of the sample is described in Tables 1 and 2 , and it was observed that most workers were young adults, women, slightly overweight, physically active, and nonsmokers. 
Table 1. Descriptive analysis of personal and occupational characteristics of a quantitative nature.

\begin{tabular}{|c|c|}
\hline & $\begin{array}{l}\text { Mean (standard } \\
\text { deviation) }\end{array}$ \\
\hline Age (years) & $37.28(10.33)$ \\
\hline Mass (kg) & $72.29(16.16)$ \\
\hline Height (m) & $1.66(0.08)$ \\
\hline Body mass index $\left(\mathrm{kg} / \mathrm{m}^{2}\right)$ & $25.81(4.60)$ \\
\hline Total working time (months) & $107.46(97.86)$ \\
\hline Weekly workload (h) & $33.98(15.11)$ \\
\hline $\begin{array}{l}\text { Numerical Pain Rating Scale } \\
\text { (score, } 0-10)\end{array}$ & $3.71(2.88)$ \\
\hline \multicolumn{2}{|l|}{ Work Ability Index } \\
\hline Domain 1 (score 0-10) & $8.09(1.43)$ \\
\hline Domain 2 (score 2-10) & $7.96(1.44)$ \\
\hline Domain 3 (score 1-7) & $3.71(2.34)$ \\
\hline Domain 4 (score 1-6) & $5.47(0.72)$ \\
\hline Domain 5 (score 1-5) & $4.50(0.78)$ \\
\hline Domain 6 (score 1-7) & $6.36(1.56)$ \\
\hline Domain 7 (score 1-4) & $3.06(0.77)$ \\
\hline \multicolumn{2}{|l|}{ SEFIP-work } \\
\hline Neck (score 0-4) & $0.52(0.72)$ \\
\hline Shoulders (score 0-4) & $0.39(0.71)$ \\
\hline Elbows (score 0-4) & $0.08(0.40)$ \\
\hline Wrists/hands (score 0-4) & $0.30(0.62)$ \\
\hline Upper back (score 0-4) & $0.61(0.75)$ \\
\hline Lower back (score 0-4) & $0.65(0.75)$ \\
\hline Hips (score 0-4) & $0.27(0.60)$ \\
\hline Thighs (front) (score 0-4) & $0.07(0.29)$ \\
\hline Thighs (back) (score 0-4) & $0.12(0.39)$ \\
\hline Knees (score 0-4) & $0.31(0.62)$ \\
\hline Legs (front) (score 0-4) & $0.19(0.51)$ \\
\hline Calves (score 0-4) & $0.14(0.43)$ \\
\hline Ankles (score 0-4) & $0.14(0.44)$ \\
\hline Feet (score 0-4) & $0.30(0.64)$ \\
\hline Total (score 0-56) & $4.14(4.67)$ \\
\hline
\end{tabular}

SEFIP-work: Self-Estimated Functional Inability because of Pain questionnaire for workers. Work Ability Index. Domain 1: ability to work at present and compared to the best in life; Domain 2: ability to work in relation to the job requirements; Domain 3: current number of self-reported and physician-diagnosed illnesses; Domain 4: estimated loss for work due to the illnesses; Domain 5: absence from work due to the illnesses; Domain 6: own prognosis about work ability; Domain 7: mental resources.
Regarding the construct validity, we observed a correlation with magnitude above 0.50 between the SEFIP-work and the NPRS, given that these two instruments have similarity in the construct, and correlations above 0.30 between the SEFIP-work and the domains 2, 3, and 4 of the WAI, as shown in Table 3.

Regarding reliability, a subsample composed of 33 participants answered the SEFIP-work in two moments to analyze the test-retest reliability. Thus, we observed adequate reliability ( $\mathrm{ICC}=0.864)$ and internal consistency (Cronbach's alpha $=0.807$ ), as shown in Table 4 .

Table 2. Descriptive analysis of personal and occupational characteristics of a qualitative nature.

\section{Characteristics $\quad$ Number (\%)}

Sex

\begin{tabular}{l|c}
\multicolumn{1}{l|}{ Female } & $124(65.3)$ \\
\hline Male & $66(34.7)$ \\
\hline Marital status \\
\hline Single & $87(45.8)$ \\
\hline Married & $87(45.8)$ \\
\hline Divorced & $16(8.4)$ \\
\hline
\end{tabular}

Scholarity

\begin{tabular}{l|c}
\hline Complete primary level & $1(0.5)$ \\
\hline Incomplete secondary level & $1(0.5)$ \\
\hline Complete secondary level & $31(16.3)$ \\
\hline Incomplete higher education & $24(12.6)$ \\
\hline Complete higher education & $42(22.1)$ \\
\hline Incomplete postgraduate & $9(4.7)$ \\
\hline Complete postgraduate & $82(43.2)$ \\
\hline
\end{tabular}

Physical activity

\begin{tabular}{|c|c|}
\hline Yes & $101(53.2)$ \\
\hline No & $89(46.8)$ \\
\hline
\end{tabular}

Posture at work

\begin{tabular}{|c|c|}
\hline Standing & $33(17.4)$ \\
\hline Sitting & $64(33.7)$ \\
\hline Standing/sitting & $90(47.3)$ \\
\hline Standing/sitting/lying down & $3(1.6)$ \\
\hline \multicolumn{2}{|l|}{ Type of word } \\
\hline Manual & $53(27.8)$ \\
\hline Non-manual & $20(10.6)$ \\
\hline Both & $103(54.2)$ \\
\hline Others & $14(7.4)$ \\
\hline \multicolumn{2}{|l|}{ Smoking } \\
\hline Yes & $6(3.2)$ \\
\hline No & $184(96.8)$ \\
\hline
\end{tabular}


Table 3. Correlation between the self-estimated functional inability because of pain questionnaire for workers - work and the other instruments used in this study.

\begin{tabular}{|c|c|c|}
\hline \multirow[t]{2}{*}{ Instruments } & \multicolumn{2}{|c|}{$\begin{array}{l}\text { Self-estimated functional } \\
\text { inability because of pain } \\
\text { questionnaire for workers }\end{array}$} \\
\hline & rho & p-value \\
\hline $\begin{array}{l}\text { Numerical Pain } \\
\text { Rating Scale }\end{array}$ & 0.638 & $<0.001 *$ \\
\hline \multicolumn{3}{|c|}{ Work Ability Index } \\
\hline Domain 1 & -0.285 & $<0.001 *$ \\
\hline Domain 2 & -0.344 & $<0.001 *$ \\
\hline Domain 3 & -0.312 & $<0.001 *$ \\
\hline Domain 4 & -0.427 & $<0.001 *$ \\
\hline Domain 5 & -0.199 & $0.006 *$ \\
\hline Domain 6 & -0.149 & $0.041 *$ \\
\hline Domain 7 & -0.185 & 0.011 * \\
\hline
\end{tabular}

*Significant correlation ( $p<0.05$, Spearman's correlation coefficient). Work Ability Index. Domain 1: ability to work at present and compared to the best in life; Domain 2: ability to work in relation to the job requirements; Domain 3: current number of self-reported and physician-diagnosed illnesses; Domain 4: estimated loss for work due to the illnesses; Domain 5: absence from work due to the illnesses; Domain 6: own prognosis about work ability; Domain 7: mental resources.

Table 4. Reliability and internal consistency of the SEFIP-work.

\begin{tabular}{c|c|c|c|c|c} 
Test & Retest & ICC $(95 \% \mathrm{CI})$ & SEM & MDC & $\begin{array}{c}\text { Cronbach's } \\
\text { alpha }\end{array}$ \\
\hline $\begin{array}{c}2.90 \\
(2.60)\end{array}$ & $\begin{array}{c}3.57 \\
(2.92)\end{array}$ & $\begin{array}{c}0.864 \\
(0.667-0.919)\end{array}$ & 1.02 & 2.82 & 0.807 \\
\hline
\end{tabular}

ICC: intraclass correlation coefficient; Cl: confidence interval; SEM: standard error of measurement; MDC: minimum detectable change.

\section{DISCUSSION}

Our study demonstrated that the SEFIP-work is a reliable questionnaire, with adequate internal consistency, and presents satisfactory correlation with the NPRS and with the following domains of the WAI: domain 2 (ability to work in relation to the job requirements), domain 3 (current number of self-reported and physician-diagnosed illnesses), and domain 4 (estimated loss for work due to the illnesses).

This is the first study carried out verifying the measurement properties of the SEFIP in workers (SEFIP-work). However, validation studies have already been carried out with dancers (using SEFIP-dance) and athletes (using SEFIP-sport).
Similar to our study, the Turkish version of the SEFIP-dance had adequate test-retest reliability $(\mathrm{ICC}=0.807)$ and a correlation magnitude of 0.672 with the Visual Analogue Scale $(\mathrm{VAS})^{12}$. The Brazilian version of the SEFIP-sport also found adequate measurement properties, with ICC value of 0.91 , Cronbach's alpha of 0.83 and a correlation magnitude of 0.481 with the NPRS ${ }^{6}$.

Other occupational health instruments were adapted and validated for Brazilian Portuguese: Rapid Upper Limb Assessment to measure the biomechanical exposure ${ }^{13}$, Rapid Entire Body Assessment to measure the biomechanical risks present in the workplace $^{14}$, Quick Exposure Check to assess the perception of workers regarding the task demands and work conditions ${ }^{15}$, and Rapid Office Strain Assessment to measure the computer office work with risk levels ${ }^{16}$. However, no instrument available for use presents the main characteristic of the SEFIP-work: generating a numerical and interpretable disability score considering 14 parts of the body.

This study has limitations that should be highlighted. Data collection was performed using an online platform. Thus, no clinical assessment was performed to understand musculoskeletal pain and the occupational environment was not assessed. Therefore, the clinical and occupational characteristics were based on self-report.

\section{CONCLUSION}

SEFIP-work is a reliable and valid instrument to be used in Brazilian workers with musculoskeletal pain.

\section{AUTHORS" CONTRIBUTIONS}

JSPM: Conceptualization, Data curation, Formal Analysis, Methodology, Writing - original draft. AVDF: Conceptualization, Data curation, Formal Analysis, Methodology, Project administration, Writing - review and editing. CMO: Conceptualization, Data curation, Formal Analysis, Methodology, Writing - original draft. CABP: Conceptualization, Data curation, Formal Analysis, Methodology, Writing - original draft. DSR: Conceptualization, Data curation, Formal Analysis, Methodology, Writing - original draft. GNS: Data curation, Formal Analysis, Methodology, Writing - original draft. CAFPG: Conceptualization, Data curation, Formal Analysis, Methodology, Writing - review and editing. DBD: Conceptualization, Data curation, Formal Analysis, Methodology, Project administration, Writing review and editing. 


\section{REFERENCES}

1. Jumbo S, MacDermid J, Kalu M, Packham T, Athwal G, Faber K. Measurement properties of the Brief Pain Inventory-Short Form (BPI-SF) and revised short McGill Pain questionnaire version-2 (SF-MPQ-2) in pain-related musculoskeletal conditions: a systematic review. Clin J Pain. 2021;37(6):454-74. https:// doi.org/10.1097/AJP.0000000000000933

2. Dickinson CE, Campion K, Foster AF, Newman SJ, O'Rourke AM, Thomas PG. Questionnaire development: an examination of the Nordic Musculoskeletal questionnaire. Appl Ergon. 1992;23(3):197-201. https://doi.org/10.1016/00036870(92)90225-k

3. Pinheiro CAB, Gomes CAFP, Barros VS, Melo JSP, Dibai DB, Dibai-Filho AV. Self-estimated functional inability because of pain questionnaire for brazilian workers with musculoskeletal pain: face and content validity. Fisioter e Pesqui. 2020;27(3):299305. https://doi.org/10.1590/1809-2950/19031027032020

4. Ramel E, Moritz $U$, Jarnlo $G$. Validation of a pain questionnaire (SEFIP) for dancers with a specially created test battery [internet]. Med Probl Perform Art. 1999 [Mar 3, 2020];14(4):196-203. Available from: https://www.sciandmed.com/mppa

5. Reis-Júnior JR, Protázio JB, Muribeca-de-Castro AM, Pinheiro JS, Takahasi HY, Pires FO, et al. Brazilian version of the Self-estimated functional inability because of Pain questionnaire for musculoskeletal injuries relating to dance and sport: translation and cross-cultural adaptation. Sao Paulo Med J. 2020;138(1):11-8. https://doi.org/10.1590/15163180.2019.0375.r1.08102019

6. Reis-Júnior JR, Pinheiro JS, Protázio JB, Pinheiro CAB, Fidelis-dePaula-Gomes CA, Oliveira Pires F, et al. Self-estimated functional inability because of pain questionnaire for athletes: a reliability and construct validity study. J Chiropr Med. 2021;20(1):23-9. https://doi.org/10.1016/J.JCM.2021.02.002

7. Prinsen CAC, Mokkink LB, Bouter LM, Alonso J, Patrick DL, Vet $\mathrm{HCW}$, et al. COSMIN guideline for systematic reviews of patientreported outcome measures. Qual Life Res. 2018;27(5):114757. https://doi.org/0.1007/s11136-018-1798-3

8. Terwee CB, Mokkink LB, Knol DL, Ostelo RWJG, Bouter LM, Vet HCW. Rating the methodological quality in systematic reviews of studies on measurement properties: a scoring system for the COSMIN checklist. Qual Life Res. 2012;21(4):651-7. https://doi.org/10.1007/s11136-011-9960-1

9. Silva Junior SHA, Vasconcelos AGG, Griep RH, Rotenberg L. Validade e confiabilidade do índice de capacidade para o trabalho (ICT) em trabalhadores de enfermagem. Cad Saude Publica. 2011;27(6):1077-87. https://doi.org/10.1590/S0102$311 \times 2011000600005$

10. Ferreira-Valente MA, Pais-Ribeiro JL, Jensen MP. Validity of four pain intensity rating scales. Pain. 2011;152(10):2399404. https://doi.org/10.1016/j.pain.2011.07.005

11. Fleiss JL. The design and analysis of clinical experiments. New Jersey: Wiley; 1999.

12. Yurt $Y$, Yakut $Y$, Sener G. AB1106 validity and reliability of turkish version of self estimated functional inability because of pain (SEFIP) questionnaire and determination of pain profile in a turkish folk dancer group. Ann Rheum Dis. 2013;71(Suppl 3):701. https://doi.org/10.1136/annrheumdis2012-eular.1104

13. Valentim DP, Sato TO, Comper MLC, Silva AM, Boas CV, Padula RS. Reliability, construct validity and interpretability of the Brazilian version of the Rapid Upper Limb Assessment (RULA) and Strain Index (SI). Brazilian J Phys Ther. 2018;22(3):198204. https://doi.org/10.1016/j.bjpt.2017.08.003

14. Lamarão AM, Costa LC, Comper ML, Padula RS. Translation, cross-cultural adaptation to Brazilian- Portuguese and reliability analysis of the instrument Rapid Entire Body Assessment-REBA. Braz J Phys Ther. 2014;18(3):211-7. https://doi.org/10.1590/ bjpt-rbf.2014.0035

15. Comper MLC, Costa LOP, Padula RS. Quick Exposure Check (QEC): a cross-cultural adaptation into Brazilian-Portuguese. Work. 2012;41(Suppl 1):2056-9. https://doi.org/10.3233/ WOR-2012-0430-2056

16. Rodrigues MS, Sonne M, Andrews DM, Tomazini LF, Sato T de O, Chaves TC. Rapid office strain assessment (ROSA): cross cultural validity, reliability and structural validity of the Brazilian-Portuguese version. Appl Ergon. 2019;75:143-54 https://doi.org/10.1016/J.APERGO.2018.09.009 